\title{
Produtividade e qualidade de figos Roxo de Valinhos submetidos à fertirrigação e ao armazenamento refrigerado
}

\author{
Diniz Fronza ${ }^{1}$, Auri Brackmann², Reimar Carlesso ${ }^{3}$, Rogério de Oliveira Anese ${ }^{4}$, Vanderlei Both ${ }^{5}$, Elizandra \\ Pivotto Pavanello ${ }^{5}$, Jonas Hamann ${ }^{6}$
}

\begin{abstract}
RESUMO
A baixa produtividade de figos no Brasil geralmente está relacionada com as deficiências hídrica e nutricional. Este trabalho teve como objetivo avaliar o efeito da fertirrigação com doses de nitrogênio e potássio sobre a produtividade e qualidade dos figos do cultivar Roxo de Valinhos durante o armazenamento refrigerado. O experimento de campo foi realizado durante dois anos, e que no último ano os frutos foram armazenados na temperatura de $0,5^{\circ} \mathrm{C}$ por 15 dias. Os tratamentos consistiram da combinação das doses de 150, 250, 350 e 450 kg ha-1 de nitrogênio (N) e 150, 250 e 350 kg ha` ${ }^{1}$ de potássio (K) fornecidas via fertirrigação. Segundo os resultados, doses de até $250 \mathrm{~kg} \mathrm{ha}^{-1}$ de N e K na fertirrigação elevam a produtividade de figos Roxo de Valinhos, e estas doses conduzem a maior produtividade entre os tratamentos avaliados. A fertirrigação aumentou em $96,7 \%$ a produtividade de figos verdes e $49 \%$ a de figos maduros em comparação ao tratamento padrão. Os níveis de $\mathrm{N}, \mathrm{K}$ e a forma de aplicação não influenciam a qualidade dos frutos durante o armazenamento refrigerado.
\end{abstract}

Palavras-chave: Ficus carica L., nutrição mineral, armazenamento, qualidade.

\section{ABSTRACT}

\section{Effect of fertigation and cold storage on yield and quality of 'Roxo de Valinhos' figs}

The low productivity of figs in Brazil is usually associated with water and nutrition deficiency. The aim of this work was evaluate the effect of fertigation with doses of nitrogen and potassium on yield and quality of the 'Roxo de Valinhos' figs during cold storage. The field experiment was conducted during two years, and in the last year, the fruits were stored at $0.5^{\circ} \mathrm{C}$ for fifteen days. The treatments were a combination of doses of of nitrogen (150, 250, 350 and 450 $\mathrm{kg} \mathrm{ha}^{-1}$ ) and potassium (150, 250 and $350 \mathrm{~kg} \mathrm{ha}^{-1}$ ) applied by fertigation. The results showed that doses up to $250 \mathrm{~kg}^{-}$ ${ }^{1}$ of $\mathrm{N}$ and $\mathrm{K}$ in fertigation increased the yield of 'Roxo de Valinhos' figs, and these doses increased the yield among the treatments. Fertigation increased yield of green figs by by $96.7 \%$ and ripe figs by $49 \%$ compared with the control. The rates of $\mathrm{N}$ and $\mathrm{K}$ and the application form did not affect the fruit quality during cold storage.

Key words: Ficus carica L., mineral nutrition, quality, storage.

\footnotetext{
Recebido para publicação em novembro de 2009 e aprovado em junho de 2010

${ }^{11}$ Engenheiro Agrônomo, Doutor. Departamento de Fruticultura, Colégio Politécnico da Universidade Federal de Santa Maria (UFSM), Av. Roraima, Bairro Camobi, nº 1000, prédio 70, 97105-900, Santa Maria, Rio Grande do Sul, Brasil. dinizfronza@yahoo.com.br

${ }^{2}$ Engenheiro Agrônomo, Doutor. Departamento de Fitotecnia, Universidade Federal de Santa Maria, Av. Roraima, Bairro Camobi, nº 1000, 97105-900, Santa Maria, Rio Grande do Sul, Brasil. auribrackmann@gmail.com

${ }^{3}$ Engenheiro Agrônomo, Doutor. Departamento de Engenharia Rural, Universidade Federal de Santa Maria, Av. Roraima, Bairro Camobi, ${ }^{\circ}$ 1000, 97105-900, Santa Maria, Rio Grande do Sul, Brasil. E-mail: carlesso@ccr.ufsm.br

${ }^{4}$ Técnico Agrícola, Acadêmico de Agronomia. Departamento de Fitotecnia, Universidade Federal de Santa Maria, Av. Roraima, Bairro Camobi, ${ }^{\circ}$ 1000, 97105-900, Santa Maria, Rio Grande do Sul, Brasil. rogerio_anese@yahoo.com.br

${ }^{5}$ Acadêmico de Agronomia. Departamento de Fitotecnia, Universidade Federal de Santa Maria, Av. Roraima, Bairro Camobi, nº 1000, 97105-900, Santa Maria, Rio Grande do Sul, Brasil.vanderleiboth@yahoo.com.br, elizandra_pavanello@yahoo.com.br

${ }^{6}$ Técnico Agrícola, Aluno do Curso de Agroindústria do Colégio Politécnico da Universidade Federal de Santa Maria (UFSM), Av. Roraima, Bairro Camobi, n ${ }^{1000,}$, prédio 70, 97105-900, Santa Maria, Rio Grande do Sul, Brasil. jonas.agroindustria@yahoo.com.br.
} 


\section{INTRODUÇÃO}

A figueira (Ficus carica L.), originária do Oriente Médio, apresenta boa adaptação aos climas subtropical úmido e temperado, o que possibilita seu cultivo em diversas regiões, como é o caso do Sudeste do Brasil. Seus frutos possuem excelente sabor para o consumo in natura, porém sua vida pós-colheita é curta, mesmo quando armazenados sob refrigeração (Neves et al., 2002). A produção nacional em 2007 ultrapassou 26.000 toneladas, no entanto, a produtividade média é baixa, ficando em torno de oito toneladas por hectare (Corrêa et al., 2008). Uma técnica capaz de maximizar a produtividade é a fertirrigação, já que ela está diretamente associada ao fornecimento de água e nutrientes (Almeida \& Silveira, 1997). A fertirrigação é um sistema de cultivo que se caracteriza pelo fornecimento de nutrientes às plantas através da água da irrigação (Villas Bôas, 2001). No que diz respeito à nutrição mineral da figueira, alguns elementos são requeridos em maior quantidade por essa frutífera, como é o caso do potássio $(\mathrm{K})$ e do nitrogênio (N), os quais estão presentes em maior concentração nos figos (Hiroce et al., 1979).

O potássio é um elemento de extrema importância para o funcionamento celular, pois na planta é responsável por funções como mudanças de turgor nas células-guarda durante o movimento estomático, ativador de bombas de prótons (ATPases) nas membranas, cofator de mais de 40 enzimas, dentre outras (Marschner, 1995). Além disso, esse elemento apresenta interferência na absorção de outros elementos, como é o caso do fósforo, que, conforme Barros (1982) e Brizola et al. (2005), com aumento do nível de potássio fornecido à planta também aumentam os teores de fósforo em folhas e pecíolos da figueira.

Outro elemento de suma importância é o nitrogênio, requerido em maiores quantidades, sendo a sua disponibilidade limitante do crescimento das plantas. Esse elemento faz parte de um grande número de moléculas, como aminoácidos, ácidos nucleicos (DNA e RNA) e clorofilas (Marschner, 1995). O seu fornecimento via fertirrigação maximiza o efeito da aplicação, eliminando uma das formas de perda de $\mathrm{N}$ para a atmosfera, a volatilização por amônia $\left(\mathrm{NH}_{3}^{+}\right)$, pois o nitrogênio já está solubilizado. A perda por $\mathrm{NH}_{3}^{+}$ocorre devido ao baixo teor de umidade no solo no momento da aplicação do fertilizante, já que a água libera prótons para a transformação da amônia em amônio $\left(\mathrm{NH}_{4}^{+}\right)$, que apresenta baixa mobilidade no perfil do solo e é facilmente absorvido pela planta (Bissani et al., 2004).

Para a cultura de figueira, informações referentes à nutrição mineral na literatura são escassas (Leonel \& Junior, 2008), principalmente nas condições brasileiras de figos Roxo de Valinhos. No entanto, alguns avanços foram obtidos com outros cultivares, tendo a maioria das pesquisas comparado a fertilização com o estado nutricional da figueira e poucas estudaram a relação da nutrição com o rendimento e a qualidade dos frutos (Aksoy et al., 1987, citado por Irget et al.,2008; Anaç et al., 1992, citado por Irget et al., 2008). Irget et al. (1999), aplicando potássio via foliar, concluíram que esse elemento afetou positivamente o tamanho, a firmeza e coloração dos frutos. Aksoy et al. (1987), citados por Irget et al. (2008) e Anaç et al. (1992), citados por Irget et al. (2008), reportam que o aumento da aplicação de potássio resultou em melhoria da coloração e do sabor dos figos. Irget et al. (2008) relatam que na Turquia a nutrição de figueira apresenta problemas de deficiências de N, K, Ca e B.

O armazenamento refrigerado é uma forma de prolongar o período pós-colheita de muitos frutos pela redução de suas atividades metabólicas, como respiração e produção de etileno (Chitarra \& Chitarra, 2005). Em frutos como maçã, caqui e pêssego, o armazenamento refrigerado possibilita o aumento da vida pós-colheita em até quatro meses para maçã e dois para caqui e pêssego (Brackmann et al., 2003, 2008; Sestari et al., 2008). Com isso, possibilita o transporte de frutos a longa distância (Paula et al., 2007), além de maior período de tempo para a comercialização, que, para figos, pode alcançar em torno de 10 dias (Neves, et al., 2002). Para figos maduros, as temperaturas entre - 0,5 e $1,0^{\circ} \mathrm{C}$ apresentam-se como adequadas para manutenção da qualidade de figos (Neves, et al. 2002; Chitarra \& Chitarra, 2005; Lima et al., 2005; Paula et al., 2007).

O objetivo deste trabalho foi avaliar o efeito da fertirrigação com doses de nitrogênio e potássio sobre a produtividade e a qualidade de figos cultivar Roxo de Valinhos durante o armazenamento refrigerado de figos.

\section{MATERIAL E MÉTODOS}

O experimento foi conduzido no pomar da área experimental o Setor de Fruticultura do Colégio Politécnico da Universidade Federal de Santa Maria - RS (latitude: $29^{\circ}$ 43‘S, longitude: $53^{\circ} 43^{\prime} \mathrm{W}$, altitude: $96 \mathrm{~m}$ ). O clima da região, segundo a classificação de KÖPPEN, classifica-se como subtropical úmido (Cfa), com verões quentes (Moreno 1961). De acordo com Streck et al. (2008), o solo da área é classificado como Argissolo Amarelo distrófico, típico de textura franca.

O período de condução do trabalho foi de setembro de 2005 a junho de 2007, num pomar de figueira cv. Roxo de Valinhos no terceiro ano de produção, instalado com espaçamento de 2,0 x 2,5 m e conduzido com 16 ramos produtivos. Na área onde está instalado o pomar utilizou- 
se cobertura morta de aveia cultivada no inverno anterior e para o controle de plantas daninhas empregou-se o herbicida Glifosato. A área do pomar recebeu aplicação de fosfato natural como fonte de fósforo. Utilizou-se uma fileira de plantas de figueira ao redor do pomar como bordadura. As unidades experimentais foram separadas por uma lona plástica enterrada na profundidade de 0,50 $\mathrm{m}$, distanciadas 1,0 m do tronco da planta na linha e 1,25 m nas fileiras. O delineamento experimental utilizado foi em blocos casualizados (DBC).

O solo da área do pomar apresentava as seguintes características químicas, no momento da instalação do experimento: $\mathrm{pH}_{\text {água }}=5,5, \mathrm{CTC}_{\text {efet }}=9,1 \mathrm{Cmol}_{\mathrm{c}} \mathrm{dm}^{-1}, \mathrm{Al}=$ $0 \%$; Bases $=67 \% ; \mathrm{SMP}=6,0 ; \mathrm{MO}=2,9 \%$; Argila $=$

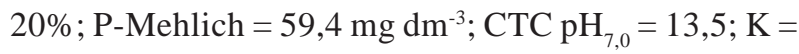
$90,0 \mathrm{mg} \mathrm{dm}^{-3} ; \mathrm{Cu}=4,8 \mathrm{mg} \mathrm{dm}^{-3} ; \mathrm{Zn}=5,7 \mathrm{mg} \mathrm{dm}^{-3} ;$ e B $=$ $0,5 \mathrm{mg} \mathrm{dm}^{-3}$.

Os tratamentos correspondentes a doses de nitrogênio $(\mathrm{N})$ e potássio (K) foram obtidos pela mistura de $30 \%$ de ureia e $70 \%$ de nitrato de cálcio para N, e para K utilizou-se o cloreto de potássio. Esses compostos foram diluídos na água e posteriormente fornecidos às plantas via irrigação por gotejamento. Os tratamentos avaliados neste experimento consistiram de irrigação com adubação básica, sem irrigação e fertirrigação com doses de $\mathrm{N}$ e K, os quais estão apresentados a seguir, sendo $\mathrm{kg}$ de $\mathrm{N} \mathrm{ha}^{-1}$ e kg de $\mathrm{K} \mathrm{ha}^{-1}$, respectivamente: [1] $150+150$; [2] $250+$ 150; [3] $350+150 ;$ [ [4] $450+150 ;[5] 150+250 ;[6] 250+250$; [7] $350+250 ;$; 8$] 450+250 ;$ [ [9] $150+350 ;$ [ [10] $250+350$; [11] $350+350$; [12] $450+350$; [13] $250+250$ (aplicados na base com irrigação); e [14] 250 + 250 (padrão - aplicados na base sem irrigação).

As doses estabelecidas em cada tratamento foram divididas em 10 partes iguais, sendo solubilizadas e fornecidas às plantas via irrigação por gotejamento durante o ciclo produtivo.

As variáveis analisadas no experimento a campo foram: comprimento de ramo, obtido pela medida do comprimento do ramo do ano desde a inserção com o tronco até sua extremidade; peso médio de frutos verdes para indústria, por meio da pesagem de uma amostra de 100 frutos, os quais foram colhidos no ponto adequado para a industrialização, ou seja, fruto inchado, com coloração de casca verde intensa e partes internas com coloração branca; produtividade de frutos verdes, obtida pela multiplicação do número de frutos verdes colhidos por planta com o número total de planta por hectare; frutos por planta, obtidos pela contagem do número total de frutos colhidos por planta; diâmetro de frutos maduros, com auxílio de um paquímetro, medido na região equatorial do fruto; e produtividade de frutos maduros, obtida pela multiplicação do número de frutos maduros colhidos por planta com o número total de plantas por hectare.
Os frutos colhidos no segundo ano de realização do experimento foram levados até o Núcleo de Pesquisa em Pós-colheita da Universidade Federal de Santa Maria para serem armazenados. Eles foram armazenados em minicâmaras experimentais de $0,233 \mathrm{~m}^{3}$, as quais estavam dentro de uma câmara frigorífica de $45 \mathrm{~m}^{3}$, que permaneceu na temperatura de $0,5{ }^{\circ} \mathrm{C}( \pm 0,1)$ durante todo o período de armazenagem. A temperatura foi controlada por um termostato eletrônico, sendo diariamente acompanhada por um termômetro de bulbo de mercúrio inserido na polpa de um fruto.

Após 15 dias de armazenamento refrigerado, e mais dois de exposição a $20^{\circ} \mathrm{C}$, foram realizadas as seguintes análises: sólidos solúveis totais (SST), determinados com o auxílio de um refratômetro, sendo os resultados expressos em ${ }^{\circ}$ Brix; acidez titulável, por meio da titulação com $\mathrm{NaOH}(0,01 \mathrm{~N})$ de 1,0 mL de suco diluído em $100 \mathrm{~mL}$ de água, sendo os resultados expressos em meq $100 \mathrm{~mL}^{-1}$; incidência de podridões, obtida pela contagem de frutos que apresentavam sinais de ataque de patógenos causadores de podridões, sendo os resultados expressos em percentagem de frutos podres; rachadura, pela contagem de frutos que apresentavam rachaduras na casca, sendo os resultados expressos em percentagem; e coloração da epiderme, medida por uma escala de cor de 0 a 3, em que índice 0: até $25 \%$ de coloração roxa; 1: de 25 a 50\%, 2: de 50 a 75\%; e 3: maior que $75 \%$ de coloração roxa, sendo os resultados expressos pela escala de cor obtida pela fórmula $=\left[\left(\mathrm{n}^{\circ}\right.\right.$ frutos $\mathrm{x} 0)+\left(\mathrm{n}^{\circ}\right.$ frutos $\left.\mathrm{x} 1\right)+\left(\mathrm{n}^{\circ}\right.$ frutos $\left.\mathrm{x} 2\right)+\left(\mathrm{n}^{\circ}\right.$ frutos $\mathrm{x} 3)] / \mathrm{n}^{\circ}$ total de frutos da amostra.

Para cada variável avaliada efetuou-se análise de variância, sendo as médias comparadas pelo teste de Scottknott a 5\% de probabilidade de erro. As variáveis expressas em percentagem, devido a não apresentarem distribuição normal, foram transformadas pela fórmula $\operatorname{arc.sen} \sqrt{\mathrm{x} / 100}$ antes da análise da variância, sendo apresentadas na forma original para melhor compreensão dos resultados.

\section{RESULTADOS E DISCUSSÃO}

Para a variável comprimento de ramos, não houve diferença estatística para as condições analisadas (dados não apresentados).

Com base nos resultados para a produtividade de figos verdes para industrialização, obtidos no primeiro ano de avaliação do experimento, a dose de $250 \mathrm{~kg} \mathrm{ha}^{-1}$ de $\mathrm{N}$ associado a $250 \mathrm{~kg} \mathrm{ha}^{-1}$ de $\mathrm{K}$ apresentou rendimento de 14,6 toneladas por hectare, sendo $96,7 \%$ superior ao tratamento padrão (Tabela 1). Essa produtividade pode ser considerada alta, pois está acima das obtidas na maioria dos pomares de figos brasileiros. 
Esse resultado esta de acordo com Pereira (1981), o qual afirma que para obtenção de uma melhor produtividade de figos deve-se aplicar em torno de 200 a 300 $\mathrm{kg} \mathrm{ha}^{-1}$ de $\mathrm{N}$ e 200 a $500 \mathrm{~kg} \mathrm{ha}^{-1}$ de K.
Já para a produtividade de figos maduros, realizada no segundo ano do experimento, a dose de $250 \mathrm{~kg} \mathrm{ha}^{-1}$ de $\mathrm{N}$ associado a $150 \mathrm{~kg} \mathrm{ha}^{-1}$ de $\mathrm{K}$ foi a que apresentou a maior produtividade, porém não teve diferença estatística da

Tabela 1. Produtividade, número de frutos por planta, diâmetro de frutos e peso de figos verdes cultivar Roxo de Valinhos submetidos à fertirrigação com doses de $\mathrm{N}$ e K.

\begin{tabular}{|c|c|c|c|c|c|}
\hline & 2005-06 & & 2006-07 & & \\
\hline $\begin{array}{c}\text { Tratamento } \\
\qquad \mathbf{N}+\mathbf{K} \\
\left(\mathbf{k g ~ h a}^{-1}\right)\end{array}$ & $\begin{array}{l}\text { Produtividade de } \\
\text { frutos verdes } \\
\text { (t ha-1) }\end{array}$ & $\begin{array}{l}\text { Peso médio de } \\
\text { frutos verdes } \\
\text { (g) }\end{array}$ & $\begin{array}{c}\text { Frutos } \\
\text { por planta }\end{array}$ & $\begin{array}{c}\text { Diâmetro de } \\
\text { frutos maduros } \\
(\mathrm{cm})\end{array}$ & $\begin{array}{c}\text { Produtividade de } \\
\text { frutos maduros } \\
\text { (t ha-1) }\end{array}$ \\
\hline $150+150^{*}$ & $8,65 b^{* *}$ & $19,3 \mathrm{a}$ & 232,3 a & $5,06 \mathrm{a}$ & $27,5 \mathrm{a}$ \\
\hline $250+150$ & $9,88 \mathrm{~b}$ & $19,2 \mathrm{a}$ & 267,0 a & $5,06 \mathrm{a}$ & $32,4 \mathrm{a}$ \\
\hline $350+150$ & $9,36 \mathrm{~b}$ & 18,6 a & 243,7 a & $5,03 \mathrm{a}$ & 28,3 a \\
\hline $450+150$ & $7,95 \mathrm{~b}$ & 16,3 a & 246,0 a & 4,95 a & 27,8 a \\
\hline $150+250$ & 13,3 a & 19,8 a & $221,0 \mathrm{a}$ & 5,09 a & 25,9 b \\
\hline $250+250$ & $14,6 \mathrm{a}$ & $17,8 \mathrm{a}$ & 238,0 a & $5,08 \mathrm{a}$ & $28,1 \mathrm{a}$ \\
\hline $350+250$ & $11,8 \mathrm{a}$ & $18,4 \mathrm{a}$ & 244,7 a & 4,99 a & $29,1 \mathrm{a}$ \\
\hline $450+250$ & $12,3 \mathrm{a}$ & $17,8 \mathrm{a}$ & 277,7 a & $5,10 \mathrm{a}$ & $29,8 \mathrm{a}$ \\
\hline $150+350$ & $10,2 \mathrm{~b}$ & $20,1 \mathrm{a}$ & 215,3 a & $4,93 \mathrm{a}$ & $24,1 \mathrm{~b}$ \\
\hline $250+350$ & $11,0 \mathrm{a}$ & $19,0 \mathrm{a}$ & 260,0 a & $4,97 \mathrm{a}$ & $29,7 \mathrm{a}$ \\
\hline $350+350$ & $11,1 \mathrm{a}$ & $16,7 \mathrm{a}$ & 209,3 a & 4,99 a & $24,1 \mathrm{~b}$ \\
\hline $450+350$ & $11,6 \mathrm{a}$ & $21,2 \mathrm{a}$ & 259,3 a & $5,05 \mathrm{a}$ & $31,3 \mathrm{a}$ \\
\hline $250+250^{* * *}$ & $10,3 \mathrm{~b}$ & $19,8 \mathrm{a}$ & 180,3 a & $4,91 \mathrm{a}$ & $21,0 \mathrm{~b}$ \\
\hline $250+250^{* * * *}$ & $7,42 \mathrm{~b}$ & 18,9 a & 210,0 a & $4,78 \mathrm{a}$ & $21,7 \mathrm{~b}$ \\
\hline$\overline{\mathrm{CV}(\%)}$ & 16,6 & 11,1 & 15,6 & 2,86 & 14,4 \\
\hline
\end{tabular}

* Nos tratamento $1^{\circ}$ ao $12^{\circ}$, o nitrogênio e o potássio foram aplicados via fertirrigação

** Médias seguidas pelas mesmas letras não diferem entre si pelo teste de Scott-knott a 5\% de probabilidade de erro.

*** Irrigado, $\mathrm{N}$ e K aplicados na base.

***** Sem irrigação, N e K aplicados na base.

Tabela 2. Qualidade físico-química de figos Roxo de Valinhos em razão da dose de N e K aplicada através de fertirrigação, após 15 dias de armazenamento a $0,5^{\circ} \mathrm{C}$ mais dois dias a $20^{\circ} \mathrm{C}$.

\begin{tabular}{|c|c|c|c|c|c|}
\hline $\begin{array}{c}\text { Tratamento } \\
\mathbf{N}+\mathbf{K} \\
\left(\mathbf{k g h a}^{-1}\right)\end{array}$ & $\begin{array}{c}\text { SST } \\
\left({ }^{\circ} \text { Brix }\right)\end{array}$ & $\begin{array}{c}\text { Acidez } \\
\left(\mathrm{meq}^{\left.100 \mathrm{~mL}^{-1}\right)}\right.\end{array}$ & $\begin{array}{c}\text { Incidência } \\
\text { de Podridões } \\
(\%)\end{array}$ & $\begin{array}{c}\text { Frutos } \\
\text { Rachados } \\
(\%)\end{array}$ & $\begin{array}{l}\text { Cor da epiderme } \\
\text { (Escala 0-3) }\end{array}$ \\
\hline $150+150^{*}$ & $12,3 a^{* *}$ & $1,98 \mathrm{a}$ & $30,1 \mathrm{a}$ & $15,8 \mathrm{a}$ & $2,45 \mathrm{a}$ \\
\hline $250+150$ & $12,6 \mathrm{a}$ & 2,15 a & $37,8 \mathrm{a}$ & 17,5 a & $2,80 \mathrm{a}$ \\
\hline $350+150$ & 13,0 a & 2,05 a & $42,7 \mathrm{a}$ & $27,4 \mathrm{a}$ & $2,77 \mathrm{a}$ \\
\hline $450+150$ & $12,4 \mathrm{a}$ & $2,43 \mathrm{a}$ & $28,8 \mathrm{a}$ & $14,1 \mathrm{a}$ & $2,45 \mathrm{a}$ \\
\hline $150+250$ & 12,8 a & $2,08 \mathrm{a}$ & 29,5 a & $33,8 \mathrm{a}$ & $2,68 \mathrm{a}$ \\
\hline $250+250$ & 11,9 a & $2,30 \mathrm{a}$ & $25,2 \mathrm{a}$ & $14,6 \mathrm{a}$ & $2,38 \mathrm{a}$ \\
\hline $350+250$ & 12,6 a & $2,25 \mathrm{a}$ & $43,4 \mathrm{a}$ & $35,1 \mathrm{a}$ & $2,36 \mathrm{a}$ \\
\hline $450+250$ & 12,9 a & $2,53 \mathrm{a}$ & $28,8 \mathrm{a}$ & $8,10 \mathrm{a}$ & $2,59 \mathrm{a}$ \\
\hline $150+350$ & $12,3 \mathrm{a}$ & $2,35 \mathrm{a}$ & $25,8 \mathrm{a}$ & $12,5 \mathrm{a}$ & $2,85 \mathrm{a}$ \\
\hline $250+350$ & 11,8 a & $2,00 \mathrm{a}$ & $22,8 \mathrm{a}$ & 16,9 a & $2,37 \mathrm{a}$ \\
\hline $350+350$ & $12,2 \mathrm{a}$ & $2,28 \mathrm{a}$ & $22,7 \mathrm{a}$ & 15,9 a & $2,00 \mathrm{a}$ \\
\hline $450+350$ & $12,8 \mathrm{a}$ & 2,08 a & $25,5 \mathrm{a}$ & $16,5 \mathrm{a}$ & $2,50 \mathrm{a}$ \\
\hline $250+250^{* * *}$ & $12,6 \mathrm{a}$ & $2,15 \mathrm{a}$ & $12,1 \mathrm{a}$ & $2,10 \mathrm{a}$ & 2,79 a \\
\hline $250+250^{* * * *}$ & 12,5 a & $1,75 \mathrm{a}$ & 28,6 a & $16,1 \mathrm{a}$ & $2,84 \mathrm{a}$ \\
\hline$\overline{\mathrm{CV}(\%)}$ & 4,46 & 16,1 & 39,9 & 62,8 & 13,4 \\
\hline
\end{tabular}

* Nos tratamento $1^{\circ}$ ao $12^{\circ}$ o nitrogênio e o potássio foram aplicados via fertirrgação

** Médias seguidas pelas mesmas letras não diferem entre si pelo teste de Scott-knott a 5\% de probabilidade de erro.

*** Irrigado, N e K aplicados na base.

*** Padrão sem irrigação, N e K aplicados na base 
maioria das outras condições de fertirrigação para essa variável (Tabela 1). Com essas dosagens de nutrientes, conseguiu-se produtividade de 32,4 t ha-1, sendo $49 \%$ superior ao tratamento-padrão, estando acima da média brasileira, que, segundo Corrêa et al. (2008), fica em torno de $8 \mathrm{t} \mathrm{ha}^{-1}$. Certamente, esses resultados são decorrentes da aplicação de N e K solubilizados na água de irrigação, os quais são absorvidos em maior quantidade pelas raízes por estarem na forma iônica.

O número de frutos por planta não foi influenciado pelas diferentes doses de $\mathrm{N}$ e K fornecidas via fertirrigação (Tabela 1). O tratamento que recebeu adubação com N e K no solo e posterior irrigação apresentou o menor número de frutos por planta. Provavelmente, houve maior lixiviação de $\mathrm{NO}^{-3}$ e/ou volatilização da $\mathrm{NH}^{+3}$ e escorrimento superficial do K, diminuindo assim a absorção e o aproveitamento da adubação fornecida. Assim, o conhecimento de alguns aspectos nutricionais e hídricos é informação crucial para o sucesso na atividade da ficicultura (Leonel \& Tecchio, 2008).

Para o diâmetro de frutos, a fertirrigação com as doses de $250 \mathrm{~kg} \mathrm{ha}^{-1}$ de K associado a 150, 250 e $450 \mathrm{~kg} \mathrm{ha}^{-1}$ de N foi superior ao tratamento sem irrigação; no entanto, não apresentou diferença estatística (Tabela 1). O nitrogênio afeta o crescimento e/ou tamanho dos frutos, alterando tanto o calibre quanto o número de frutos produzidos (Dolinski, et al., 2005), já o potássio, além de seu efeito direto na planta, é responsável também pela potencialização da resposta do nitrogênio (Marschner, 1995). O peso médio de frutos verdes apresentou-se maior nas doses com $450 \mathrm{~kg} \mathrm{ha}^{-1}$ de $\mathrm{N}$ mais $350 \mathrm{~kg} \mathrm{ha}^{-1}$ de K; no entanto, não diferiu estatisticamente do tratamento-padrão, com $\mathrm{N}$ e K aplicados na base sem irrigação (Tabela 1).

Após o período de armazenamento não houve diferença estatística entre os tratamentos nas características de qualidade dos frutos (Tabela 2). Pode-se observar que o tratamento somente com irrigação e N e K no solo apresentou menor incidência de podridões e rachaduras, no entanto não diferiu estatisticamente das demais condições. Provavelmente, as diferentes doses de $\mathrm{N}$ e K fornecidas às plantas não provocaram grandes alterações no metabolismo do fruto e, por isso, demonstraram comportamento semelhante durante o armazenamento.

\section{CONCLUSÃO}

Para as condições em que foi desenvolvido o experimento, a fertirrigação com doses de até $250 \mathrm{~kg} \mathrm{ha}^{-1}$ de $\mathrm{N}$ e K aumenta em 96,7\% a produtividade de figos verdes e $49 \%$ a de figos maduros em relação ao tratamento padrão. Os níveis de N, K e a forma de aplicação não influenciam a qualidade dos frutos durante o armazenamento refrigerado.

\section{REFERÊNCIAS}

Almeida MM \& Silveira ET (1997) Tratos culturais da figueira no sudoeste de Minas Gerais. Informe Agropecuário, 18:27-33.

Barros JCSM (1982) Teores de nutrientes e suas relações em tecidos de figueira (Ficus carica L.) cultivada em solução nutritiva. Dissertação de Mestrado. Faculdade de Agronomia "Eliseu Maciel”-Universidade Federal de Pelotas, Pelotas. 60p.

Bissani CA, Gianello C, Tedesco MJ \& Camargo FAO (2004) Fertilidade dos solos e manejo da adubação de culturas. Genesis, Porto Alegre, Genesis. 322p.

Brizola RMO, Leonel S, Tecchio MA \& Hora RC (2005). Teores de macronutrientes em pecíolos e folhas de figueira (Ficus carica 1.) em função da adubação potássica. Ciência e Agrotecnologia, 29:610-616.

Brackmann A, Freitas ST, Mello AM \& Steffens CA (2003) Aplicação de 1-MCP em caqui 'Quioto' armazenado sob refrigeração e atmosfera controlada. Revista Brasileira de Fruticultura, 25:42-44.

Brackmann A, Weber A, Pinto JAV, Neuwald DA \& Steffens CA (2008) Manutenção da qualidade pós-colheita de maçãs 'Royal Gala' e 'Galaxi' sob armazenamento em atmosfera controlada. Ciência Rural, 38:2478-2484.

Chitarra MIF \& Chitarra AB (2005) Pós-colheita de frutas e hortaliças: fisiologia e manuseio. Lavras, UFLA, v1. 783p.

Correa S, Silveira D, Santos C, Lindemann C, Reetz ER \& Beling RR (2008) Anuário brasileiro de fruticultura. Santa Cruz do Sul, Gazeta Santa Cruz. 136p.

Dolinski MA, Serrat BM, Motta ACV, Cuquel FL, Souza SR, Mayde-mio LL \& Monteiro LB (2005) Produção, teor foliar e qualidade de frutos do pessegueiro 'Chimarrita' em função da adubação nitrogenada, na região da Lapa-PR. Revista Brasileira de Fruticultura, 27:295-299.

Hiroce R, Olima M \& Gallo JR (1979) Composição mineral e exportação de nutrientes pelas colheitas de frutos subtropicais e temperados. In: Congresso Brasileiro de Fruticultura, Pelotas. Anais, Sociedade Brasileira de Fruticultura. p.179-189.

Irget ME, Aydýn S, Oktay M, Tutam M, Aksoy U \& Nalbant M (1999) Effect of foliar potassium nitrate and calcium nitrate application on nutrient content and fruit quality of fig. In: Anac \& Martin-Pre-vel (Eds.) Improved Crop Quality by Nutrient Management. Nova Yourk, Kluwer Academic Publishers. p.81-85.

Irget ME, Aksoy U, Okur B, Ongun AR \& Tepecik M (2008) Effect of calcium based fertilization on dried fig (Ficus carica L. cv. Sarýlop) yield and quality. Scientia Horticulturae, 118:308-313.

Leonel S \& Tecchio MA (2008) Produção da figueira submetida a diferentes épocas de poda e irrigação. Revista Brasileira de Fruticultura, 30:1015-1021.

Leonel S \& Junior ERD (2008) Efeitos do esterco de curral na fertilidade do solo, no estado nutricional e na produção da figueira. Revista Brasileira de Fruticultura, 30:534-539.

Lima LC, Dias MSC, Castro MV, Martins RN, Junior PMR \& Silva EB (2005) Conservação pós-colheita de figos verdes (ficus carica) cv. Roxo de Valinhos tratados com hipoclorito de sódio e armazenados sob refrigeração em atmosfera modificada passiva. Ciência e Agrotecnologia, 29:810-816.

Marschner H (1995) Mineral nutrition of higher plants. London, Academic Press. 674p.

Moreno JA (1961) Clima do Rio Grande do Sul. Porto Alegre, Secretaria da Agricultura, Diretoria de Terras e Colonização, Secção de Geografia. 43p. 
Neves LC, Rodrigues AC \& Vieites RL (2002) Polietileno de baixa densidade (pebd) na conservação pós-colheita de figos cv. "Roxo de Valinhos”. Revista Brasileira de Fruticultura, 24:057-062.

Pereira FM (1981) Cultura da figueira. Piracicaba, Livro Ceres. 73p.

Paula LA, Isepon JS \& Correa LS (2007) Qualidade pós-colheita de figos do cv Roxo de Valinhos com aplicação de cloreto de cálcio e fungicidas. Acta Scientiarum Agronomy, 29:41-46.

Sestari I, Giehl RFH, Pinto JAV \& Brackmann, A (2008) Condições de atmosfera controlada para pêssegos 'Maciel' colhidos em dois estádios de maturação. Ciência Rural, 38:1240-1245.
Streck EV, Kampf N, Dalmolin RSD, Klamt E, Nascimento PC, Scheneider P, Giasson E \& Pinto LFS (2008) Solos do Rio Grande do Sul. $2^{\text {a }}$ Ed. Porto Alegre, EMATER/RS-ASCAR. 222p.

Villas Bôas RL (2001) Doses de nitrogênio para o pimentão aplicadas de forma convencional e através da fertirrigação. Tese de Doutorado. FCA/UNESP, Botucatu. 123p. 